Research Article

\title{
Characteristics of Corrosion Related to Ash Deposition on Boiler Heating Surface during Cofiring of Coal and Biomass
}

\author{
Yongzheng Wang (D), Yu Sun, Lei Jiang, Lu Liu, and Yungang Li \\ School of Energy and Power Engineering, Shandong University, Jinan 250061, China \\ Correspondence should be addressed to Yongzheng Wang; sddxwyz@163.com
}

Received 1 November 2019; Accepted 30 December 2019; Published 24 January 2020

Guest Editor: Yanqing Niu

Copyright (c) 2020 Yongzheng Wang et al. This is an open access article distributed under the Creative Commons Attribution License, which permits unrestricted use, distribution, and reproduction in any medium, provided the original work is properly cited.

In order to investigate the regularity and mechanism of corrosion related to ash deposition on the boiler heating surface during cofiring of coal and biomass, the influence of fuel property, type of metal tubes (heating surface), proportion of blended biomass, and atmosphere in the furnace was studied by using the static corrosion mass gain method with the hightemperature tube furnace system. The results indicated that the effect of biomass property on ash corrosion is greater than that of coal, which was mainly due to high content of alkali metals and chlorine in biomass fuels. The corrosion resistance of metal pipes is T91 > 12CrMoVG > 20G. T91 is the most appropriate one, and it can effectively inhibit chlorine corrosion and can be used as the ideal material for the biomass-fired boiler and the biomass and coal cofired boiler. In addition, ash deposition can significantly aggravate the corrosion of metal tubes, and the degree of corrosion tends to become significant with increasing proportion of blended biomass fuels. $\mathrm{HCl}$ can aggravate metal corrosion, which can be inhibited by $\mathrm{SO}_{2}$.

\section{Introduction}

Because of the depletion of fossil fuels and their environmental pollution all over the world, the development and utilization of clean renewable energy has gradually drawn more attention, in which biomass energy receives much attention for its characteristics, including easy to burn and low emission of $\mathrm{CO}_{2}, \mathrm{SO}_{\mathrm{x}}, \mathrm{NO}_{\mathrm{x}}$, and other pollutants [1]. However, biomass fuels are generally low in heat value and also difficult to collect, transport, and store. There are problems in utilization of biomass such as high investment costs and low utilization efficiency. These problems can be solved by the biomass and coal co-combustion technology. The volatile content in biomass fuels is generally higher, typically more than $60 \%$. With a small amount of blended biomass fuels, the ignition temperature of coal can be greatly reduced and ignition performance can be improved. Meanwhile, the equipment of cofiring of biomass and coal can be transformed from the original coal-fired equipment, which is more economical $[2,3]$.
Biomass fuels usually contain more alkali metals, alkaliearth metals, chlorine, and other elements. During biomass combustion, chlorine is released in the form of $\mathrm{HCl}$ and $\mathrm{Cl}_{2}$, reacting with the metal heating surface, causing severe active oxidation corrosion $[4,5]$. Also, it can promote the gasification of the alkali metal elements in the fuel and react with alkali metals to form volatile alkali chloride in the gas phase [6]. The vast majority of gaseous alkali metals are deposited and condensed on the low-temperature metal heating surface. Furthermore, they trap solid particles in flue gas, which leads to serious slagging, fouling, and corrosion. The boiler parameters of an advanced coal-fired power plant are in the supercritical and ultra-supercritical states, and the parameters of a biomass boiler are still limited to high temperature and high pressure, which greatly restrains the improvement of boiler efficiency. High-temperature corrosion has always been a major obstacle to improve the boiler steam parameters. The temperature of a high-temperature superheater in a Danish biomass boiler must always be in control within $580^{\circ} \mathrm{C}$. Main steam parameters of a Chinese biomass boiler 
also tend to control within $450^{\circ} \mathrm{C}$ to avoid high-temperature corrosion, which is a serious disorder in massive scale utilization of the biomass energy $[7,8]$.

High-temperature chloride corrosion of biomass can be eased by cofiring with coal or additives. A biomass and coal cofiring boiler can reach the same steam parameters as the coal-fired boiler; at the same time, it can ensure the low emission of pollutants [9]. In biomass and coal cofiring boilers, due to the high content of $\mathrm{Si}$ and $\mathrm{Al}$ in coal, most of the alkali metals exist in the form of aluminosilicate with lower reactivity and higher melting point, thus decreasing the content of chlorine and viscosity of the ash deposition, which means the corrosion related to ash deposition is slowed down [10]. Due to the high content of sulfur in coal, the $\mathrm{SO}_{2}$ content in the atmosphere increases, which leads to sulfur oxide corrosion. Meanwhile, the composition of the deposition becomes complicated. If the content of alkali in the fuel is high, sulfur oxide will conduct complex reactions with the alkali to form low-melting point compound sulfate, focal sulfate, and other complex low-temperature comelts, which lead to local liquid phase appearance. The protective oxide film on the surface of the tube wall is damaged, thus resulting in more corrosion [11].

Due to the reaction of multiphase gases, liquids, and solids, the combustion mechanism of biomass cofiring with coal is more complicated. The high content of chlorine in the biomass and sulfur in the coal will cause serious ash deposition and corrosion problems on the heat exchange surface of the boiler, which reduce the heat transfer efficiency of the heating surface and even harm the boiler operation safety. It has become one of the most serious problems restricting the application of biomass combustion. Therefore, this research focuses on the corrosion related to ash deposition during biomass and coal cofiring. By simulating the cofiring environment of biomass and coal, the regularity and mechanism of corrosion related to ash deposition during cofiring of biomass and coal under different fuel properties, type of metal tubes (heating surface), proportion of blended biomass, and atmosphere in the furnace were explored. It provides a theoretical basis for the effective utilization of biomass fuels and the optimization of boiler operating parameters.

\section{Materials and Methods}

2.1. Experimental Samples. Common crops in Shandong province are used as biomass fuels: straw, corn stalk, and cotton stalk. Lean coal and bitumite are used as blended coal. Proximate and ultimate analysis of fuels is shown in Table 1 . Table 2 shows the elemental analysis of ashes. The data in the tables are the weight percentage. Before the experiment, fuels are separately ground to 20 mesh. and dried in the drying oven at a constant temperature of $100^{\circ} \mathrm{C}$ and then stored under seal. Experimental ash samples are fired according to the standard material (coal ash) using a mixture of biomass fuels and coal by weight ratio [12]. The proportion of blended biomass is $0 \%, 20 \%, 50 \%, 70 \%$, and $100 \%$. The metal samples $12 \mathrm{CrMoVG}, 20 \mathrm{G}$, and T91 are taken from power plants in Shandong. Through wire cutting and other metal processing methods, the samples are made into $20 \mathrm{~mm} \times 3 \mathrm{~mm} \times 3 \mathrm{~mm}$ standard size. The metal samples are polished before experiment using 200, 500 , and 1000 grit sand paper sequentially in order to remove the last traces and get a unified standard sample surface. Their size is measured by a vernier caliper to calculate the surface area, followed by washing in acetone to remove the fouling on the metal surface. After drying with a filter paper, they are placed in the drying oven at a constant temperature $100^{\circ} \mathrm{C}$ for $20 \mathrm{~min}$. The chemical composition of the metal materials is shown in Table 3.

2.2. Experimental System. The experimental system is shown in Figure 1. Due to the higher content of chlorine in biomass fuels, it mainly exists in the form of $\mathrm{HCl}$ in the combustion process, and sulfur in the coal is almost completely oxidized to $\mathrm{SO}_{2}$. Therefore, this experiment mainly investigates corrosion characteristics of ash deposits under the coexistence atmosphere of sulfur chlorine in the gas phase. In the mixed gas, $\mathrm{N}_{2}$ is the balance gas. The concentration of $\mathrm{O}_{2}$ is kept at $6 \%$, while $\mathrm{CO}_{2}$ is maintained at $12 \%$. The content of $\mathrm{HCl}$ and $\mathrm{SO}_{2}$ is adjusted through a flow meter. They are mixed well in the gas mixing device in order to simulate the flue gas atmosphere in the boiler superheater [13]. The high-temperature reaction part adopts a horizontal tube furnace electric heating system. The temperature is under precise control by using an intelligent PDI temperature controller and solid state relay (SSR). The temperature difference between the constant temperature section in the reaction zone is less than $5^{\circ} \mathrm{C}$. Exhaust gas treatment adopts $\mathrm{NaOH}$ solution to absorb excess $\mathrm{SO}_{2}$ and $\mathrm{HCl}$ to avoid polluting the environment.

2.3. Experimental Procedure. The metal samples are coated with the synthetic deposits: first, the deposited sample are prepared in a suspension liquid with anhydrous ethanol, smeared evenly it on the surface of metal samples, and the amount of plaster is controlled at $15 \mathrm{mg} / \mathrm{cm}^{2}$. Then, the samples are placed into the oven at a constant temperature of $100^{\circ} \mathrm{C}$ for $20 \mathrm{~min}$ to remove the residual ethanol solution. The metal samples covered with synthetic deposits are placed into the constant temperature section of the horizontal tube furnace to carry out the corrosion experiment. The concentration of $\mathrm{HCl}$ and $\mathrm{SO}_{2}$ is changed to investigate the effect of different atmospheres on corrosion. The total air flow is controlled at $120 \mathrm{~mL} / \mathrm{min}$, and the temperature is controlled at $600^{\circ} \mathrm{C}$. Preliminary experiments show that the corrosion weight gain of samples increases rapidly in the early stage (within 15-20h), but tends to be stable in the later stage. [9]. The whole process presents the regularity of a similar parabola curve. For the convenience of quantitative analysis, the parabola fitting for the corroded weight curve is carried out. The equation is as follows:

$$
\Delta G=k \tau^{1 / 2}+C,
$$

where $k$ is a rate constant of the parabolic curve, characterizing the reaction rate of corrosion, and $C$ is the 
Table 1: Proximate and ultimate analysis of fuels (air-dried) (\%).

\begin{tabular}{lccccccccccc}
\hline \multirow{2}{*}{ Fuel } & \multirow{2}{*}{ Sample number } & \multicolumn{3}{c}{ Proximate analysis } & \multicolumn{4}{c}{ Ultimate analysis } \\
& & $\mathrm{M}_{\mathrm{ad}}$ & $\mathrm{A}_{\mathrm{ad}}$ & $\mathrm{V}_{\mathrm{ad}}$ & $\mathrm{FC}_{\mathrm{ad}}$ & $\mathrm{C}_{\mathrm{ad}}$ & $\mathrm{O}_{\mathrm{ad}}$ & $\mathrm{H}_{\mathrm{ad}}$ & $\mathrm{N}_{\mathrm{ad}}$ & $\mathrm{S}_{\mathrm{ad}}$ & $\mathrm{Cl}_{\mathrm{ad}}$ \\
\hline Straw & $\mathrm{B} 1$ & 8.22 & 7.05 & 65.62 & 19.11 & 40.87 & 37.22 & 5.71 & 0.78 & 0.15 & 0.31 \\
Corn stalk & $\mathrm{B} 2$ & 7.96 & 8.32 & 65.46 & 18.26 & 40.51 & 36.58 & 5.83 & 0.67 & 0.13 & 0.065 \\
Cotton stalk & $\mathrm{B} 3$ & 5.67 & 4.23 & 69.74 & 21.38 & 44.26 & 38.94 & 6.32 & 0.50 & 0.08 & 0.074 \\
Bitumite & $\mathrm{C} 1$ & 4.35 & 20.69 & 35.18 & 39.79 & 61.02 & 7.54 & 4.01 & 1.18 & 1.21 & - \\
Lean coal & $\mathrm{C} 2$ & 1.30 & 34.94 & 10.15 & 53.62 & 55.27 & 3.27 & 2.96 & 0.61 & 1.65 & - \\
\hline
\end{tabular}

TABLE 2: Major ash constituents in fuels (\%).

\begin{tabular}{lccccccc}
\hline Fuel & $\mathrm{K}$ & $\mathrm{Na}$ & $\mathrm{Ca}$ & $\mathrm{Mg}$ & $\mathrm{Al}$ & $\mathrm{Si}$ & $\mathrm{Fe}$ \\
\hline Straw & 1.96 & 0.78 & 0.84 & 0.072 & 1.69 & 1.83 & 0.17 \\
Corn stalk & 1.88 & 0.64 & 1.20 & 0.069 & 3.16 & 2.24 & 0.16 \\
Cotton stalk & 0.86 & 0.35 & 0.84 & - & 1.65 & 0.51 & 0.25 \\
Bitumite & 0.081 & 0.11 & 1.05 & 0.50 & 15.87 & 21.71 & 3.99 \\
Lean coal & 0.098 & 0.16 & 1.61 & 0.86 & 15.38 & 24.36 & 5.66 \\
\hline
\end{tabular}

integration constant, indicating the deviation of the parabola curve on the initial corrosion reaction caused by kinds of factors. The following experimental cycle is selected: $30 \mathrm{~h}$, weighed every $6 \mathrm{~h}$, in order to obtain a corrosion mass gain curve. For analyzing the cross section of the corrosion layer, the metal sample is first fixed with the epoxy resin and cured at normal temperature for 24 hours. It is cut transversely with a small cutter, and then the cross section is polished with a polisher. The SEM is used to observe the morphological characteristics of the corrosion layer on the cross section of the metal sample; the energy dispersive spectrometer (EDS) is used to detect the elemental composition of several regions in the corrosion layer.

\section{Results and Discussion}

3.1. Effect of Fuel Property on Deposit Corrosion. Deposit corrosion properties are quite different because of the difference in characteristics of biomass fuels. In this paper, common biomass fuels (wheat straw, corn stalk and cotton stalk) and different types of coals (lean coal and bituminous coal) are blended to combust in the weight ratio of $1: 1$ to study the effect on deposit corrosion caused by different fuel characteristics under the coexistence atmosphere of sulfur and chlorine. Figure 2 shows the fitting curve of the increased weight for $12 \mathrm{CrMoVG}$ metal samples under the coexistence atmosphere of sulfur and chlorine using different synthetic deposits at $600^{\circ} \mathrm{C}$. The fitted correlations are shown in Table $4 . R^{2}$ in Table 4 represents a coefficient of determination or a goodness of fit, which refers to the degree to which the regression line fits the observed value. The value of $R^{2}$ in the table is close to 1 , indicating that the regression line fits the observations well.

It can be seen from Figure 2 that the weight of metal samples increases with time. It increases faster in the initial stage and gradually decreases in the later stage. The corrosion weight curve is approximately parabola. This is because, in the initial stage, the oxidative corrosion reaction rate is high and a thin oxide layer is quickly formed on the metal surface. As the corrosion reaction continues, the oxide layer gradually becomes thicker, preventing the metal from direct contact with the reactants and slowing down the corrosion reaction. The corrosion weight of the metal samples increases with time, and its variation curve is parabola: $\Delta G=k \tau^{1 / 2}$. The corrosion is intensified when the samples are covered by deposits. And it shows significant difference in the degree of corrosion with the changes in fuel properties. The corrosion performance of biomass fuels from strong to week is as follows: wheat straw, corn stalk, and cotton stalk. The corrosion of lean coal is more intense than bituminous coal when the same biomass fuel blends with different coals.

From analysis of rate constant $k$ of the parabolic curve in Table 4, it can be seen that the effect of biomass fuels is significantly greater than the effect of coal. The component of deposits varies widely as the fuel characteristics, combustion conditions, and other factors. Lith et al. [13] suggest that the corrosion in the process of cofiring of biomass and coal is mainly based on the alkali metals existed in deposits. They react directly with the wall metal of the heat exchanger, causing the corrosion of the metal matrix. Also, they generate low-temperature eutectic with other compounds. Sometimes, it can even cause serious electrochemical corrosion. So, the damage of deposit corrosion is larger.

Ash deposition mainly exacerbates corrosion through two effects. First, the corrosive salts such as $\mathrm{KCl}$ and $\mathrm{NaCl}$ directly chemically react with the metal, resulting in intensified active oxidative corrosion at the heating surface; second, the formation of complex low-temperature eutectic melts destroys the oxide film on the metal surface and causes electrochemical corrosion. From the content of major ash constituents in Table 2, it can be seen that the content of alkali metals and chlorine is the highest in wheat straw. The alkali metal content in corn stalk is slightly lower than that in straw. However, the chlorine content is significantly lower than that of wheat straw. The cotton stalk and corn stalk have a similar chlorine content. However, it is lowest for alkali metal content in cotton stalk, even less than half of the two former. So, it is visible that the component of alkali metals and chloride in biomass fuels are the main cause of ash deposit corrosion. The component of alkali metals and chlorine in biomass fuels is obviously higher than that in the coal. Also, there is a large difference. So the effect of the difference between biomass fuels on corrosion is larger than the effect of the coal.

During cofiring of coal and biomass, due to the fixing effect of $\mathrm{Al}$ and $\mathrm{Si}$ in the ash on the alkali metals, most of the chlorine released in the form of gas phase $\mathrm{HCl}$ or $\mathrm{Cl}_{2}$, the 
TABLE 3: Elemental composition of the heating surface metal (\%).

\begin{tabular}{lcccccccccc}
\hline Steel & $\mathrm{C}$ & $\mathrm{S}$ & $\mathrm{P}$ & $\mathrm{Si}$ & $\mathrm{Mn}$ & $\mathrm{Cr}$ & $\mathrm{Mo}$ & $\mathrm{V}$ & $\mathrm{Cu}$ & $\mathrm{Ni}$ \\
\hline 12CrMoVG & $0.08 \sim 0.15$ & $\leq 0.03$ & $\leq 0.03$ & $0.17 \sim 0.37$ & $0.40 \sim 0.70$ & $0.90 \sim 1.20$ & $0.25 \sim 0.35$ & $0.15 \sim 0.30$ & $\leq 0.20$ & $\leq 0.25$ \\
20G & $0.17 \sim 0.24$ & $\leq 0.03$ & $\leq 0.03$ & $0.17 \sim 0.37$ & $0.35 \sim 0.65$ & - & - & - & - & - \\
T91 & $0.08 \sim 0.12$ & $\leq 0.02$ & $\leq 0.02$ & $0.02 \sim 0.50$ & $0.30 \sim 0.60$ & $8.00 \sim 9.50$ & $0.85 \sim 1.05$ & $0.18 \sim 0.25$ & - & $\leq 0.40$ \\
\hline
\end{tabular}

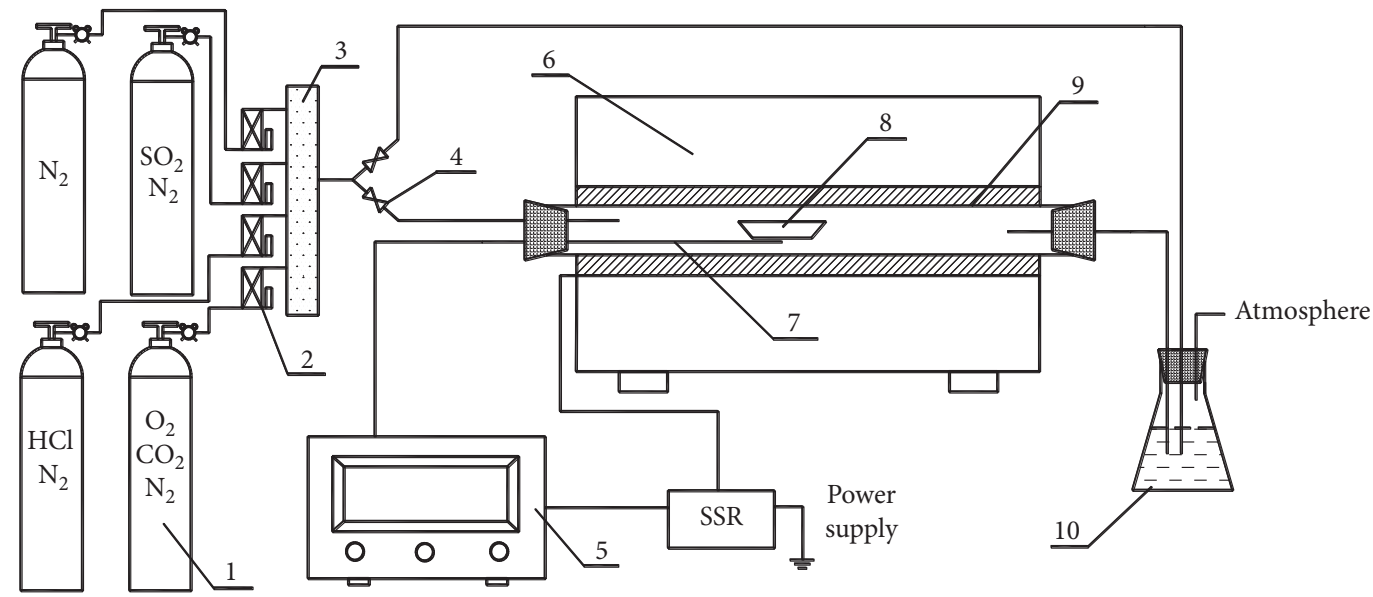

Figure 1: The schematic diagram of the experimental system. 1, gas cylinder; 2, gas flowmeter; 3, mixing equipment; 4, gas valve; 5, PID temperature controller; 6 , tube furnace; 7 , thermocouple; 8 , porcelain boat; 9 , corundum tube; 10 , absorber bottle.

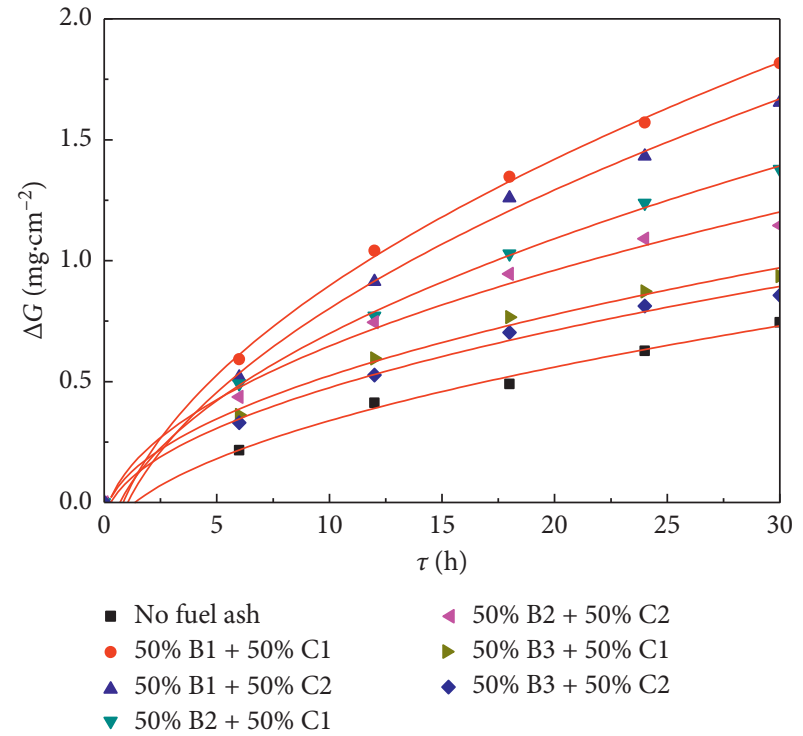

FIgURE 2: Curves of corrosion mass gain of different metal samples coated with different fuel ash.

alkali metal was mostly in the form of silicate, aluminosilicate, and sulfate, and only a very small amount of $\mathrm{Cl}$ remained in the ash, and the chemical activity of the ash was relatively stable. Generally, $\mathrm{Ca}$ and $\mathrm{Mg}$ in fuels do not exist in the form of chlorides during combustion, but they still affect the content of active corrosion components in the ash by complex reactions. When the content of $\mathrm{Ca}$ or $\mathrm{Mg}$ in fuels is high, most of the $\mathrm{Al}$ will react with it to form compounds such as $\mathrm{MgAl}_{2} \mathrm{O}_{4}, \mathrm{CaAl}_{2} \mathrm{O}_{4}$, etc., so that the fixation of $\mathrm{Al}$ to the alkali metal is weakened, and the content of alkali metal chloride in the ash is correspondingly increased.
There is a high content of ash in lean coal and bitumite. The composition of the oxide in ash is based on $\mathrm{SiO}_{2}$ and $\mathrm{Al}_{2} \mathrm{O}_{3}[14]$ and is mostly considered to be inert. Through the study, Li et al. [15] find that the oxide from ash can be divided into basic oxide and acidic oxide, where the basic oxide has lower ionic energy as important composition of low-melting eutectic mostly. Alkali metals and alkali-earth metals content such as $\mathrm{Na}, \mathrm{K}, \mathrm{Ca}, \mathrm{Mg}$, and others in the ash of lean coals is higher than that of bitumite coals. The alkaline component in ash generated by cofiring of the same biomass fuels and lean coals is certainly higher than bitumite coals. So, it results in increase in the content of low-melting point eutectic in deposits, which can accelerate the corrosion. Meanwhile, sulfur content of lean coal is high. It can be also easy to cause the molten salt corrosion of alkali metal sulfate in deposits [11]:

$$
\begin{gathered}
\mathrm{Na}_{2} \mathrm{SO}_{4}+\mathrm{SO}_{2}+\frac{1}{2} \mathrm{O}_{2} \longrightarrow \mathrm{Na}_{2} \mathrm{~S}_{2} \mathrm{O}_{7} \\
3 \mathrm{Na}_{2} \mathrm{~S}_{2} \mathrm{O}_{7}+\mathrm{Fe}_{2} \mathrm{O}_{3} \longrightarrow 2 \mathrm{Na}_{3} \mathrm{Fe}\left(\mathrm{SO}_{4}\right)_{3} \\
2 \mathrm{Na}_{3} \mathrm{Fe}\left(\mathrm{SO}_{4}\right)_{3}+4 \mathrm{Fe}+\mathrm{O}_{2} \longrightarrow 3 \mathrm{Na}_{2} \mathrm{SO}_{4}+2 \mathrm{Fe}_{3} \mathrm{O}_{4}+3 \mathrm{SO}_{2}
\end{gathered}
$$

3.2. Effect of Pipe Components on Deposit Corrosion. The deposit corrosion of the superheater varies while the pipe components are different. Under simulated condition, the contents of $\mathrm{HCl}$ and $\mathrm{SO}_{2}$ in the flue gas are both $500 \mu \mathrm{L} / \mathrm{L}$, and blended percent of straw and lean coal is, respectively, $50 \%$. The fitting curve and fitting correlation of the corrosion weight gains of the tube metal materials including 12CrMoVG, 20G and T91 are shown in Figure 3. It can be 
TABLE 4: Fitting correlations of corrosion mass gain of different metal samples coated with different fuel ash.

\begin{tabular}{lcrr}
\hline Fuels & Fitting correlations $\left(\Delta G=k \tau^{1 / 2}+C\right)$ & $k$ & $R^{2}$ \\
\hline No fuel ash & $\Delta G=0.1695 \tau^{1 / 2}-0.19802$ & 0.1695 & 0.98618 \\
$50 \%$ B1 + 50\%C1 & $\Delta G=0.39923 \tau^{1 / 2}-0.36598$ & 0.3992 & 0.99751 \\
$50 \%$ B1 + 50\%C2 & $\Delta G=0.37439 \tau^{1 / 2}-0.38188$ & 0.3744 & 0.99388 \\
$50 \%$ B2 + 50\%C1 & $\Delta G=0.29955 \tau^{1 / 2}-0.24879$ & 0.2996 & 0.99752 \\
$50 \%$ B2 + 50\%C2 & $\Delta G=0.23953 \tau^{1 / 2}-0.11091$ & 0.2395 & 0.96897 \\
$50 \%$ B3 + 50\%C1 & $\Delta G=0.19297 \tau^{1 / 2}-0.08606$ & 0.1930 & 0.97963 \\
$50 \%$ B3 + 50\%C2 & $\Delta G=0.18106 \tau^{1 / 2}-0.09793$ & 0.1811 & 0.97704 \\
\hline
\end{tabular}

seen that the corrosion resistance of three kinds of metal materials from strong to weak is T91, 12CrMoVG, and 20G. The corrosion resistance of T91 is much higher than that of the latter two. From the beginning of the reaction to about $10 \mathrm{~h}$, the increase in corrosion mass gain appears to be not obvious. The corrosion resistance of $12 \mathrm{CrMoVG}$ is slightly better than that of 20G. Nevertheless, from the corrosion reaction rate $k$, it can be seen that the difference between the two is nonobvious.

In the initial corrosion reactions, each of elements in metals participates in the corrosion reaction. $\mathrm{Cr}$ can react preferentially with oxygen in the atmosphere as a crucial element in alloy, form the oxide film with dense and adhesive properties, and produce the passivation phenomenon, so that the corrosion resistance of metals can be enhanced. However, when the temperature rises, the diffusion velocity of $\mathrm{C}$ in the interior of the metal grain is greater than that of $\mathrm{Cr}$. The formation and precipitation of carbides make the chrome poor locally near the grain boundary. $\mathrm{NaCl}$ from deposits is easy to react with metal carbide generated $\mathrm{Cl}_{2}$, which can increase the susceptibility to intergranular corrosion and cause serious intergranular corrosion. The reaction equation is as follows ( $\mathrm{M}$ represents the metal of the heat transfer surface) [16]:

$$
\mathrm{MC}+2 \mathrm{NaCl}+2 \mathrm{O}_{2} \longrightarrow \mathrm{MO}+\mathrm{Na}_{2} \mathrm{O}+\mathrm{CO}_{2}+\mathrm{Cl}_{2}
$$

The sectional micromorphology of $20 \mathrm{G}$ after the deposit corrosion experiment is shown in Figure 4. The corrosion resistance performance of $20 \mathrm{G}$ is the worst as plain carbon steel without any addition of other alloying elements. The surface of the corrosion layer is loose and porous, and there is a large gap in the surface of the metal substrate. The adhesion of the corrosion layer is poor and cannot effectively prevent the corrosive medium $\mathrm{HCl} / \mathrm{SO}_{2}$ in the gas phase from further erosion of the metal. Because of the major $\mathrm{Cl}$ element in the biomass fuel, the content of gaseous $\mathrm{HCl}$ and $\mathrm{Cl}^{-}$of deposits increases while cofiring of biomass and coal. As very small atom radius, $\mathrm{Cl}$ atom tends to agglomerate to the location of the defects on the metal heating surface, even directly pass through the oxide film on metal surface, and lead to pitting corrosion. When deposits contain alkali metal chlorides, they will directly react with the metal oxide film and continue to cause corrosion. The reaction equations are as follows:

$$
\begin{gathered}
\mathrm{Cr}_{2} \mathrm{O}_{3}+4 \mathrm{HCl}+\mathrm{H}_{2} \longrightarrow 2 \mathrm{CrCl}_{2}+3 \mathrm{H}_{2} \mathrm{O} \\
\mathrm{Cr}_{2} \mathrm{O}_{3}+4 \mathrm{NaCl}+\left(\frac{5}{2}\right) \mathrm{O}_{2} \longrightarrow 2 \mathrm{Na}_{2} \mathrm{CrO}_{4}+2 \mathrm{Cl}_{2}
\end{gathered}
$$

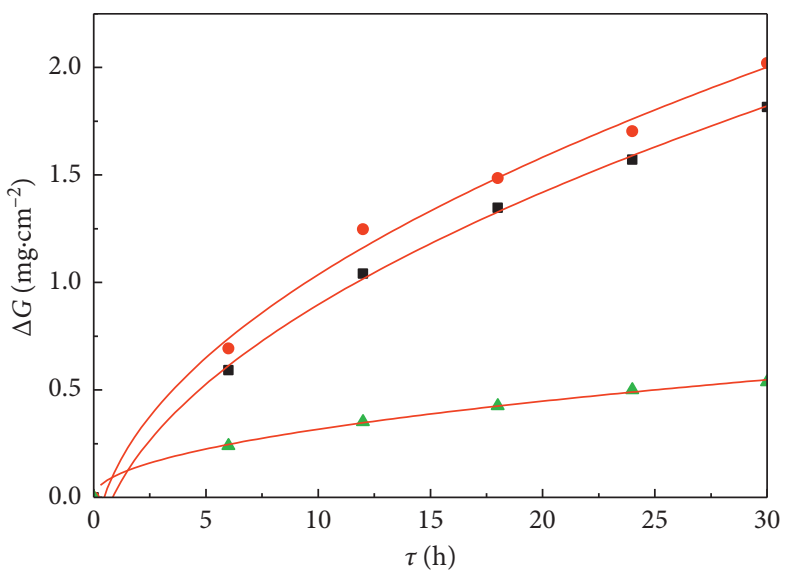

- 12CrMoVG: $\Delta G=0.3992 \tau^{1 / 2}-0.3659$
- 20G: $\Delta G=0.4171 \tau^{1 / 2}-0.2830$
- T91: $\Delta G=0.0995 \tau^{1 / 2}-0.0026$

FIgURE 3: Curves and fitting correlations of corrosion mass gain of metal samples coated with ash.

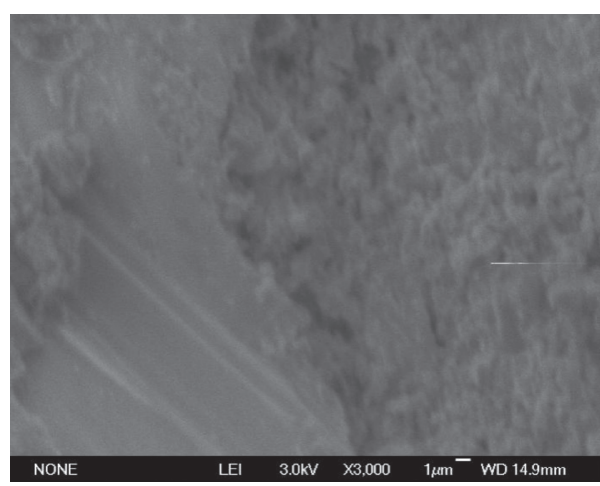

FIGURE 4: Sectional topography of 20G after deposition corrosion.

$12 \mathrm{CrMoVG}$ is superior to use as stainless steel in terms of corrosion resistance than 20G. But it is not very perfect in corrosion resistance to use for biomass-fired boiler due to the high $\mathrm{Cl}$ content in biomass fuel. Wang et al. [17] found that adding Mo and Ni elements into alloy can improve the microeutectic structure of metals, suppress the intergranular corrosion and pitting corrosion effectively, and improve the adhesion of protective oxide film, thereby improving the corrosion resistance of metals. When the Mo content is more than $3 \%$ in steel, it can significantly inhibit the penetration of $\mathrm{Cl}$ into metallic matrix. 


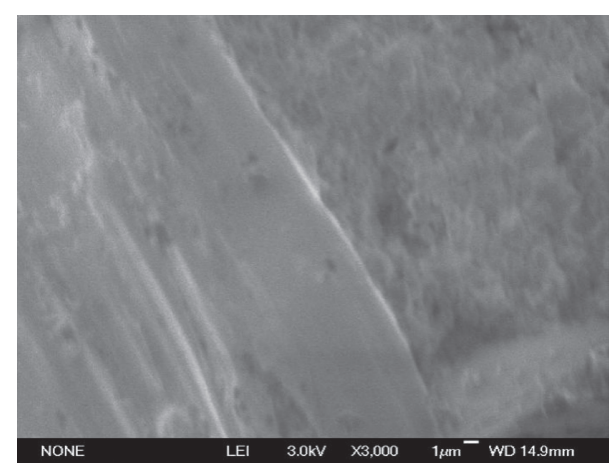

FIgURE 5: Sectional topography of T91 after deposition corrosion.

The sectional micromorphology of T91 is shown in Figure 5. For T91, Cr content is more than that of $12 \mathrm{CrMoVG}$ by an order of magnitude. The content of trace elements such as Mo and $\mathrm{Ni}$ in T91 is also higher than that in $12 \mathrm{CrMoVG}$. A dense protective film is formed between the metal matrix and the deposit corrosion layer. The corrosion film is thin and has a good combination with the metal matrix. It can isolate the metal matrix from the surrounding corrosive environment. So, the corrosion resistance is the strongest. In addition, it can be used as the ideal material for the cofiring boiler of biomass and coal.

\subsection{Effect of Proportion of Blended Fuel on Deposit Corrosion.} Figure 6 shows the fitting curve of the increased weight for $12 \mathrm{CrMoVG}$ under the coexistence atmosphere of sulfur and chlorine, using synthetic deposits with different blending ratios of wheat straw. The fitted correlations are shown in Table 5. The relation curve between the coefficient indicating corrosion rate $k$ and the proportion of blended biomass $\lambda$ is shown in Figure 7. From Figure 6, final corrosion weight of metal samples increases with the proportion of blended biomass. However, this increase does not show regularity of weighted average according to the proportion of blended biomass and coal.

When the proportion of blended wheat straw is more than $20 \%$, the ash deposit shows the obvious accelerated corrosion phenomenon on the metal samples. From 50\% to $70 \%$, it changes little for the increased corrosion weight. When the proportion of blended biomass is more than $70 \%$, the value of $k$ increases obviously. When the proportion of blended wheat straw is $100 \%$, the corrosion degree is most serious. Compared with the sample with no ash added, the weight of the metal sample with ash added increases slightly, but not significantly, while the ash is pure lean coal ash. Therefore, each composition of the ash generated by combustion of pure coal works little for the metal corrosion. In addition, the addition of lean coal in the combustion effectively inhibits the corrosion caused by wheat straw.

As shown in Table 6, from the analysis of EDS elements of different gray samples, it was found that there were significant differences in the content of the corrosive key elements in ash when different proportion of blended biomass was burning. When the proportion of blended wheat straw is $100 \%$, the content of alkali metals and chlorine in deposits is high. In addition, it is mainly in the

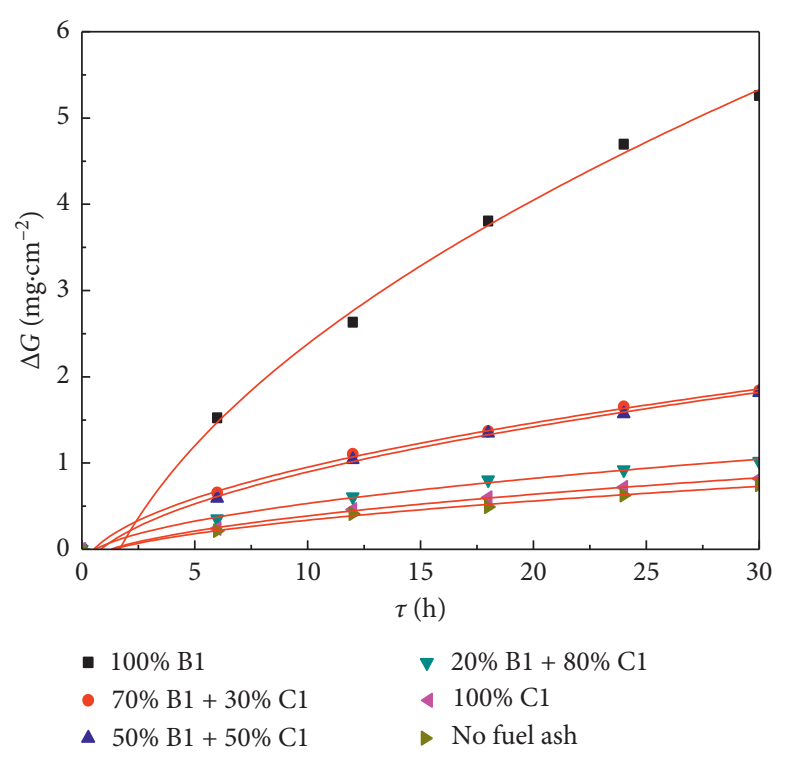

Figure 6: Curves of corrosion mass gain of metal samples coated with ash under different proportion of straw biomass blended to coal.

form of chlorides and other substances with a strong chemical reaction activity. The corrosion is the most severe: on the one hand, it can directly cause severe active oxidation corrosion; on the other hand, as the reaction is prolonged, alkali metal chloride such as $\mathrm{KCl}$ can react with the corrosion products $\mathrm{FeCl}_{2}$ and $\mathrm{CrCl}_{2}$ and produce the eutectic with a melting point of $355^{\circ} \mathrm{C}$ and $470^{\circ} \mathrm{C}$, respectively. Also, the melting point of the eutectic formed with $\mathrm{FeCl}_{3}$ is even as low as $202-220^{\circ} \mathrm{C}$ [18], thereby enabling ash deposition to appear liquid phase and resulting in more severe corrosion. The deposit corrosion activity declines significantly with the adding of the lean coal. The $\mathrm{Cl}$ content has decreased obviously while blending $50 \%$ lean coal into wheat straw. There is a high content of sulfur in lean coal. While cofiring of wheat straw and lean coal, the partial pressure of $\mathrm{SO}_{2}$ increases in the atmosphere, and the activity of alkali metal chloride decreases because of the sulfate reaction in deposits [19]. The corrosion was obviously reduced. Meanwhile, Si and $\mathrm{Al}$ elements in the coal can react with alkali metal chloride and form aluminosilicate [20], so that the corrosion of deposits has a further reduction.

When the proportion of blended wheat straw reduced from $70 \%$ to $50 \%$, the deposition corrosion degree decreased slightly, but not obvious. With the increase in lean coal blending ratio, alkali metal compounds will form lowmelting eutectics with $\mathrm{SiO}_{2}$, aluminosilicate, sulfate, etc. For example, the melting temperature of $\mathrm{K}_{2} \mathrm{O} \cdot 4 \mathrm{SiO}_{4}$ is $764^{\circ} \mathrm{C}$, and $\mathrm{KCl}-\mathrm{K}_{2} \mathrm{SO}_{4}-\mathrm{Fe}_{\mathrm{x}} \mathrm{O}_{\mathrm{y}}$ will melt at $557^{\circ} \mathrm{C}$. The appearance of some trace elements such as $\mathrm{Pb}, \mathrm{Zn}$, and $\mathrm{Ni}$ will also lead to the increase of low-temperature eutectic materials in the ash, and the local liquid phase will appear and lead to serious electrochemical corrosion $[19,21]$. With increasing proportion of blended wheat, the corrosion rate has an unconspicuous change when the proportion of blended wheat straw is lower than $20 \%$. Montgomery et al. [22] find 
TABLE 5: Fitting correlations of corrosion mass gain under different proportion of straw biomass blended to coal for metal samples coated with ash.

\begin{tabular}{|c|c|c|c|}
\hline Proportion of straw biomass blended to coal (\%) & Fitting correlations $\left(\Delta G=k \tau^{1 / 2}+C\right)$ & $k$ & $R^{2}$ \\
\hline 100 & $\Delta G=1.2737 \tau^{1 / 2}-1.6477$ & 1.2737 & 0.9945 \\
\hline 70 & $\Delta G=0.3913 \tau^{1 / 2}-0.2843$ & 0.3913 & 0.9967 \\
\hline 50 & $\Delta G=0.3992 \tau^{1 / 2}-0.3659$ & 0.3992 & 0.9975 \\
\hline 20 & $\Delta G=0.2221 \tau^{1 / 2}-0.1707$ & 0.2221 & 0.9894 \\
\hline 0 & $\Delta G=0.1906 \tau^{1 / 2}-0.2145$ & 0.1906 & 0.9969 \\
\hline No fuel ash & $\Delta G=0.1695 \tau^{1 / 2}-0.1980$ & 0.1695 & 0.9862 \\
\hline
\end{tabular}

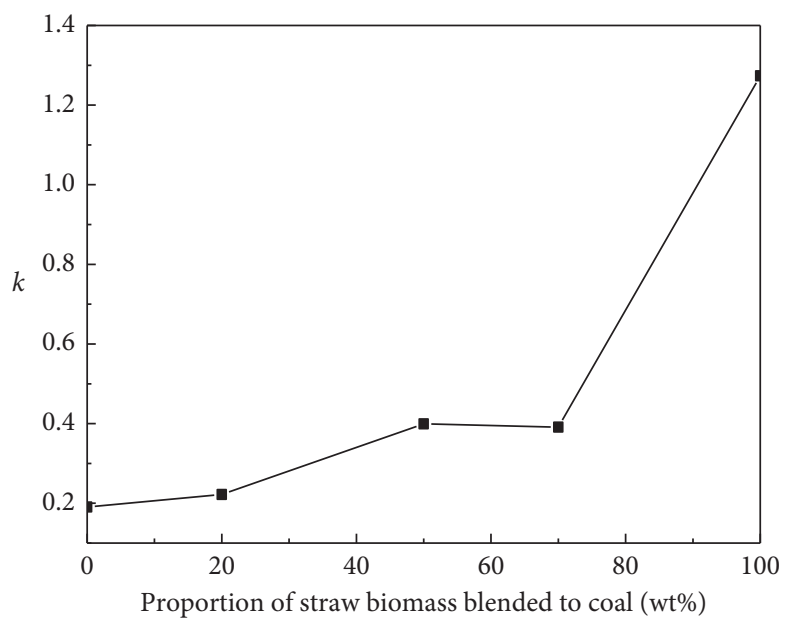

FIgURE 7: Curves of coefficient indicating corrosion rate versus proportion of straw biomass blended to coal.

TABle 6: Content of elements in different ash.

\begin{tabular}{lccccc}
\hline Element & $\mathrm{Na}$ & $\mathrm{Al}$ & $\mathrm{Si}$ & $\mathrm{S}$ & $\mathrm{Cl}$ \\
\hline Straw ash & 0.433 & 7.602 & 10.855 & 2.54 & 13.521 \\
Lean coal & 0.612 & 28.169 & 33.481 & 0.837 & 0.412 \\
50\% straw and 50\% lean coal ash & 0.498 & 17.635 & 25.282 & 3.911 & 0.649 \\
\hline
\end{tabular}

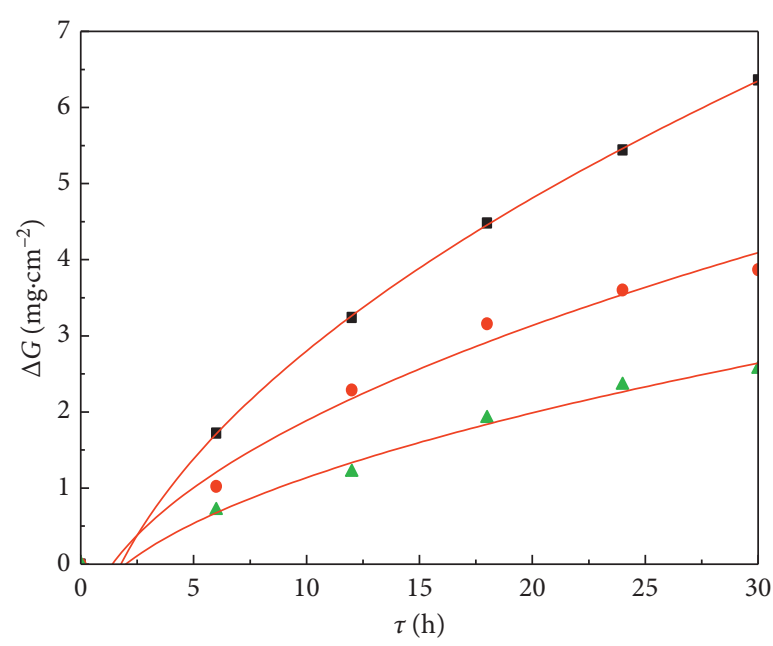

- $100 \%$ B1: $\Delta G=1.5320 \tau^{1 / 2}-2.0432$

- $70 \% \mathrm{~B} 1+30 \% \mathrm{C} 1: \Delta G=0.9534 \tau^{1 / 2}-1.1282$

$\Delta 50 \% \mathrm{~B} 1+50 \% \mathrm{C} 1: \Delta G=0.6491 \tau^{1 / 2}-0.9154$

(a)

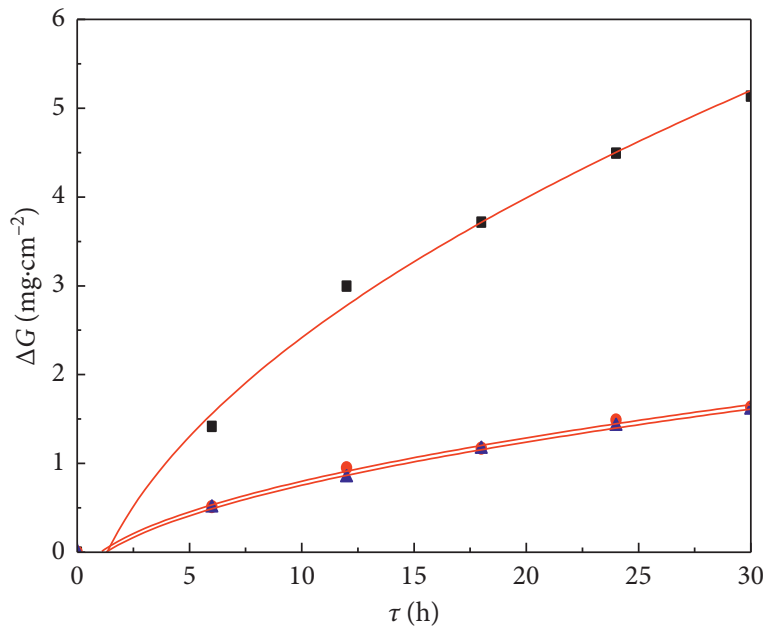

- $100 \% \mathrm{~B} 1: \Delta G=1.2018 \tau^{1 / 2}-1.3845$

- $70 \% \mathrm{~B} 1+30 \% \mathrm{C} 1: \Delta G=0.3728 \tau^{1 / 2}-0.3795$

- $50 \% \mathrm{~B} 1+50 \% \mathrm{C} 1: \Delta G=0.3709 \tau^{1 / 2}-0.4192$

(b)

FIGURE 8: Curves and fitting correlations of corrosion weight gain of the metal samples coated with ash under different atmospheres. (a) $\mathrm{HCl}: 500 \mu \mathrm{L} / \mathrm{L}$, not containing $\mathrm{SO}_{2}$. (b) $\mathrm{SO}_{2}: 500 \mu \mathrm{L} / \mathrm{L}$, not containing $\mathrm{HCl}$. 
that all $\mathrm{KCl}$ transform into noncorrosive alkali aluminosilicate while cofiring blended with $20 \%$ biomass. Then, sulfate corrosion plays a main role, but the corrosion is weakened dramatically. It is also consistent with the experimental results of this paper.

\subsection{Effect of Atmosphere in Furnace on Deposit Corrosion.} The effect of the change of the atmosphere in the furnace on deposit corrosion is shown in Figure 8. The increased weight curves and the fitting correlations when the blended proportion of wheat straw is $50 \%, 70 \%$, and $100 \%$ under the simulating flue atmosphere containing $500 \mu \mathrm{L} / \mathrm{L} \mathrm{HCl}$ only are shown in Figure 8(a) while the simulating flue only contains $500 \mu \mathrm{L} / \mathrm{L} \mathrm{SO}_{2}$ in Figure 8(b). With the increase of wheat straw ratio, it tends to be severe for the corrosion of samples when the flue gas only contains $\mathrm{HCl}$. Comparing with the situation under the coexistence atmosphere of sulfur and chlorine (Figure 6), it can be found that the degree of corrosion is intensified significantly when the proportion of blended wheat straw increases from $50 \%$ to $70 \%$ under the atmosphere of $\mathrm{HCl}$ merely. Once the $\mathrm{SO}_{2}$ is mixed, the corrosion will be inhibited obviously. Also, the increased weight of the metal samples covered with combustion ash by $70 \%$ wheat straw and lean coal is even less than $1 / 2$ of that under the $\mathrm{HCl}$ atmosphere. The corrosion rules of samples under the atmosphere containing only $500 \mu \mathrm{L} / \mathrm{L} \mathrm{SO}_{2}$ are similar with the rules under the coexistence atmosphere of sulfur and chlorine. There is a further reduction in the increased corrosion weight. However, the reduction is not obvious, and the corrosion rate does not appear to be significant. So, when the $\mathrm{SO}_{2}$ content in the atmosphere is certain, the corrosion effect of $\mathrm{HCl}$ on samples is obviously weakened.

The analysis of the above test results shows that the corrosion of the metal samples caused by the change of the atmosphere is affected by the characteristics of the deposits in the metal wall. The corrosion degree of the samples under different atmospheres tends to be severe with the increase of the blending ratio of biomass. When the simulated flue gas contains only $\mathrm{HCl}$, both $\mathrm{KCl}$ from the deposits and $\mathrm{HCl}$ from the gas can cause metal corrosion. The corrosion of the metal by $\mathrm{SO}_{2}$ is mainly reflected in the early rapid corrosion stage. As the reaction proceeds, $\mathrm{SO}_{2}$ reacts with the alkali metal salts in the ash to form products with lower activity, such as sulfate, chromate, and oxide, which can evenly cover the metal surface, and a similar passivation state appears between the metal and the gas phase interface, which inhibits further corrosion.

However, under different atmospheres, it can be seen that the corrosion of the metal samples covered with wheat straw burning ash is still very serious and is not under the control obviously with the adding of $\mathrm{SO}_{2}$. Broström et al. found that sulfation of alkali chlorides is mainly based on $\mathrm{SO}_{3}$ content in the atmosphere $[23,24]$. When the $\mathrm{KCl}$ content in deposits is high enough, the inhibitory effect of $\mathrm{SO}_{2}$ on corrosion is weakened, and the corrosion is mainly based on $\mathrm{KCl}$ from deposits. When $\mathrm{SO}_{2}$ forms a metal protective layer on the metal surface, it will undergo a sulfation reaction with $\mathrm{KCl}$ in the ash deposit, which will increase the partial pressure of $\mathrm{HCl}$ at the wall, and the active oxidative corrosion reaction of chlorine will intensify. $\mathrm{KCl}$ will also destroy the protective layer of the metal surface and intensifies the corrosion reaction.

\section{Conclusions}

(1) During cofiring of different biomass fuels with coals, characteristics of corrosion show obvious differences. Effect of corrosion from strong to weak is as follows: wheat straw, corn stalk, and cotton stalk, because the content of alkali metals and chlorine in wheat straw is significantly higher. During cofiring of the same biomass fuels with different coals, the corrosiveness of lean coal is stronger than that of bituminous coal. The content of alkaline metal oxides and sulfides in coal ash is relatively high, and it will also cause ash melt corrosion.

(2) The corrosion resistance on three kinds of common boiler metal materials is as follows: T91, 12CrMoVG, and 20G. This is because T91 contains more Cr, which can form a dense oxide film to slow down corrosion. The content of Mo and Ni is more than that in the other two metals, which improves the microeutectic structure of the metal. The corrosion resistance of $12 \mathrm{CrMoVG}$ is not much better than that of 20G. T91 can effectively inhibit the rate of corrosion, and it can be used as the ideal metal materials of the heat transfer surface in biomass and coal cofired boilers.

(3) The degree of ash deposit corrosion enhances with the increase in the proportion of blended wheat straw. Under the atmosphere with coexistence of sulfur and chlorine, when the proportion of blended wheat straw is greater than $70 \%$, the corrosion rate decreases significantly with the addition of coal. When the proportion decreases from $70 \%$ to $50 \%$, the metal corrosion weight reduces slightly. When the proportion is as low as $20 \%$, it can be regarded that alkali metal chlorides in deposits are all converted into aluminosilicate and sulfate, and the corrosion rate shows no obvious change with the increase in the proportion of blended biomass.

(4) The metal corrosion caused with the atmosphere change is influenced by the ash property. $\mathrm{HCl}$ in atmosphere can aggravate the metal corrosion. The presence of $\mathrm{SO}_{2}$ significantly inhibits $\mathrm{HCl}$ corrosion through the sulfate reaction. Especially when the proportion of blended wheat straw is below $70 \%$, the inhibitory effect of $\mathrm{SO}_{2}$ on deposit corrosion is more significant. When the proportion of blended wheat straw is $100 \%$, the presence of $\mathrm{SO}_{2}$ does not significantly inhibit corrosion due to the high $\mathrm{KCl}$ content in deposits.

\section{Data Availability}

The data used to support the findings of this study are available from the corresponding author upon request. 


\section{Conflicts of Interest}

The authors declare that there are no conflicts of interest regarding the publication of this paper.

\section{Acknowledgments}

This work was supported by Shandong Provincial Natural Science Foundation, China (ZR2017MEE009).

\section{References}

[1] H. Raclavska, D. Juchelkova, V. Roubicek, and D. Matysek, "Energy utilisation of biowaste-sunflower-seed hulls for cofiring with coal," Fuel Processing Technology, vol. 92, no. 1, pp. 13-20, 2011.

[2] Z. Ma, S. Wu, and Y. Bai, "Technical analysis on cofiring of coal and biomass," Power System Engineering, vol. 25, no. 6, pp. 1-4, 2009.

[3] T. Wang, T. Kuang, Q. Fang et al., "Experimental study of coal/biomass mixture combustion in $\mathrm{O}_{2} / \mathrm{CO}_{2}$ atmosphere," Thermal Power Generation, vol. 46, no. 4, pp. 16-21, 2017.

[4] Y. Wang, K. Zhang, L. Jiang et al., "Research on the cocorrosion characteristics of sulfur chloride in the combustion process of biomass mixed coal," Journal of University Chemical Engineering, vol. 6, pp. 1422-1429, 2015.

[5] H. J. Grabke, E. Reese, and M. Spiegel, "The effects of chlorides, hydrogen chloride, and sulfur dioxide in the oxidation of steels below deposits," Corrosion Science, vol. 37, no. 7, pp. 1023-1043, 1995.

[6] P. A. Jensen, F. J. Frandsen, K. Dam-Johansen, and B. Sander, "Experimental investigation of the transformation and release to gas phase of potassium and chlorine during straw pyrolysis," Energy \& Fuels, vol. 14, no. 6, pp. 1280-1285, 2000.

[7] Z. Wang, Y. Cao, and Z. Zhang, "Analysis and countermeasures of corrosion of high temperature superheater of biomass boiler," Zhejiang Power, vol. 35, no. 9, pp. 53-56, 2016.

[8] W. Wei, F. Huang, C. Yu et al., "Primary investigation of hightemperature corrosion problems in biomass combustion equipment," Energy Engineering, vol. 2, pp. 23-28, 2011.

[9] Y. Wang, L. Jiang, M. Yue et al., "Study on sulfur-chlorine synergistic corrosion in biomass and coal co-firing," Proceedings of the CSEE, vol. 29, no. 26, pp. 118-124, 2009.

[10] A. L. Robinson, H. Junker, and L. L. Baxter, "Pilot-scale investigation of the influence of coal-biomass cofiring on ash deposition," Energy \& Fuels, vol. 16, no. 2, pp. 343-355, 2002.

[11] Y. Zhang, L. Shi, X. Li et al., "Alkali sulfate deposits induced hot corrosion of iron based alloys at intermediate temperatures," Corrosion Science and Protection Technology, vol. 4, no. 4, pp. 250-257, 1992.

[12] X. Dong, R. Li, Z. Liu et al., "Investigation on the ash characteristic during co-firing of coal and biomass," Proceedings of the CSEE, vol. 29, no. 26, pp. 118-124, 2009.

[13] S. C. V. Lith, F. J. Frandsen, M. Montgomery, T. Vilhelmsen, and S. A. Jensen, "Lab-scale investigation of deposit-induced chlorine corrosion of superheater materials under simulated biomass-firing conditions. Part 1: exposure at $560^{\circ} \mathrm{C}$," Energy \& Fuels, vol. 23, no. 7, pp. 3457-3468, 2009.

[14] X. Li, Y. Wang, M. Yue et al., "Study on corrosion and influencing factors during co-combustion of coal and biomass," Power Station System Engineering, vol. 27, no. 6, pp. 13-15, 2011.
[15] R. Li, Y. Nie, A. Li et al., "Study on physical chemical characteristics of fly ash from municipal solid waste incinerator," Journal of Fuel Chemistry and Technology, vol. 32, no. 2, pp. 175-179, 2004.

[16] M. Mobin and A. U. Malik, "Studies on the interactions of transition metal carbides and sodium chloride in the temperature range $900-1200 \mathrm{~K}$ in oxygen," Journal of Alloys and Compounds, vol. 186, no. 1, pp. 1-14, 1992.

[17] J. Wang, G. Zhang, and S. Li, "Investigation of microstructure and corrosive behavior of NiAl-31Cr-3Mo alloy at high temperature," Mining and Metallurgical Engineering, vol. 30, no. 6, pp. 93-96, 2012.

[18] Y. Shinata, "Accelerated oxidation rate of chromium induced by sodium chloride," Oxidation of Metals, vol. 27, no. 5-6, pp. 315-332, 1987.

[19] H. P. Nielsen, F. J. Frandsen, and K. Dam-Johansen, "Labscale investigations of high-temperature corrosion phenomena in straw-fired boilers," Energy \& Fuels, vol. 13, no. 6, pp. 1114-1121, 1999.

[20] M. Montgomery and O. H. Larsen, "Field test corrosion experiments in Denmark with biomass fuels. Part 2: co-firing of straw and coal," Materials and Corrosion, vol. 53, no. 3, pp. 185-194, 2002.

[21] L. Jiang, Y. Wang, T. Yu et al., "Study on synergy corrosion mechanism of sulfur-chlorine during biomass and coal cofiring," Power System Engineering, vol. 29, no. 3, pp. 1-4, 2013.

[22] M. Montgomery, T. Vilhelmsen, and S. A. Jensen, "Potential high temperature corrosion problems due to co-firing of biomass and fossil fuels," Materials and Corrosion, vol. 59, no. 10, pp. 783-793, 2008.

[23] M. Broström, H. Kassman, A. Helgesson et al., "Sulfation of corrosive alkali chlorides by ammonium sulfate in a biomass fired CFB boiler," Fuel Processing Technology, vol. 88, no. 1112, pp. 1171-1177, 2007.

[24] K. Lisa, Y. Lu, and K. Salmenoja, "Sulfation of potassium chloride at combustion conditions," Energy \& Fuels, vol. 13, no. 6, pp. 1184-1190, 1999. 